Article

\title{
The Engagement Imperative: Experiences of Communication Practitioners' Brand Work in the Music Industry
}

\author{
Jessica Edlom \\ Department of Geography, Media and Communication, Karlstad University, Sweden; jessica.edlom@kau.se
}

Submitted: 29 April 2021 | Accepted: 24 August 2021 | Published: 20 January 2022

\begin{abstract}
Due to societal trends, such as digitalisation, platformisation, and active and co-creative audiences, new organisational practices have surfaced. This study examines how communication practitioners experience their changing work in a new communication environment in which participatory cultural norms are becoming standard in strategic communication. I argue that the requirements to produce audience engagement affect the communication work and the communication workers. This study uses the popular music industry as a case, and is based on interviews with communication practitioners as well as on the qualitative text analysis of reports and newsletters from the music marketing firm Music Ally to the music industry. The study shows that communication practitioners within the industry experience a duty to create audience engagement-an engagement imperative. Although the practitioners are highly skilled in digital communication and social media, they often see the development of digital promotional culture as a challenge and express a lack of a deeper understanding of engagement. This study highlights implications for their professional roles, competences, and identities as well as ethical implications regarding the exploitation of audiences in communication work.
\end{abstract}

\section{Keywords}

audience engagement; communication management; communication practitioner; engagement imperative; ethics; media work; music industry; participatory culture; strategic communication

Issue

This article is part of the issue "New Forms of Media Work and Its Organizational and Institutional Conditions" edited by Salla-Maaria Laaksonen (University of Helsinki) and Mikko Villi (University of Jyväskylä).

(C) 2022 by the author(s); licensee Cogitatio (Lisbon, Portugal). This article is licensed under a Creative Commons Attribution 4.0 International License (CC BY).

\section{Introduction}

In the digitalisation context, organisations have re-negotiated their communicative relationships with consumers, leading to changed patterns of communication work that consider a new organisational emphasis on audience and consumer engagement. What I call an engagement imperative now dominates communicative working practices. The engagement imperative implies that organisations' communication of all sorts is built on the precepts of creating engagement and dialogue among their audiences and stakeholders. Although audience and consumer engagement are well researched (see, for example, Barger et al., 2016; Broersma, 2019; Steensen et al., 2020), the same cannot be said about how engagement affects communication work and work- ers. Accordingly, this study examines media work in a promotional and participatory culture (cf. Deuze, 2007; Jenkins, 2006) through a qualitative analysis of music industry communication practitioners" experiences.

The popular music industry, like many others, depends on the affordances provided by platforms and social media (Choi \& Burnes, 2013; Van Dijck, 2009). As audiences (also named as consumers, users, stakeholders, and fans), are expected to engage with and "co-create" value with artist brands, new sophisticated and integrated marketing methods are adopted (Gamble et al., 2019; Scolari, 2009; Zeiser, 2015), and new communication practices to follow, foster, steer, track, and commodify consumer engagement via big data surface (Andrejevic, 2014; Choi \& Burnes, 2013; Negus, 2018). Strategy is at the centre here, and organisations 
are increasingly taking a unified approach to all sorts of deliberate and strategic communication practices (public relations [PR], marketing, and management) to adapt to changes and to build relationships with audiences (Argenti et al., 2005; Hallahan et al., 2007). Communication practitioners are part of a system and within it simultaneously play different roles-as power agents, directing debates and cultures, but also as workers acting according to norms and demands, such as new knowledge and ethical considerations. Nevertheless, there seems to be a lack of understanding of promotional practices and worker experiences (Brodmerkel \& Carah, 2016; Valentini, 2015)-and how to manage the fluidity of changing contexts within this field (Asunta, 2016; Edwards, 2018). Elmer (2011) urges us to delve more deeply into the "messiness of the profession" of PR, and Brodmerkel and Carah (2016) discuss the need to pay more attention to how algorithmic use influences the roles and the work of communication. Kiesenbauer and Zerfass (2015) argue that it has become necessary to focus more on the personal and sociocultural aspects of communication. The use of social theories in strategic communication can help us understand its sociopolitical consequences (see, for example, Ihlen \& Verhoeven, 2015), which this article helps highlight. To analyse what communication professions entail, the framework of Anteby et al. (2016) is used in this study, highlighting various parts and perspectives of the work. To also put focus on the consequences of the fast-paced and digitised field could bring insights that help create a more sustainable media industry for the workers.

Workers' experiences with participatory work is an important new approach to both the fields of media work and strategic communications. Accordingly, linking and problematising work with experiences of audience engagement will add perspectives to the communication practitioner's work conditions. I argue that the requirements of the communicators to produce audience engagement possibly affect both the work and the worker. Therefore, I explore these issues through the following research questions:

RQ1: How do the requirements to produce "engagement" affect communication work and workers in terms of the roles, responsibilities, competences, ethics, and identity of being a communication professional within the music industry?

RQ2: What are the imagined audience modes, and what are the expectations of audience engagement, from the communication professional's perspective?

This article proceeds as follows: In Section 1, I review the literature that I draw on in the analysis of media work, professional competences and identities, and strategic communication. This is followed by a presentation of the methodology used and the study conducted-interviews with communication practitioners and content analysis of music industry material. This is followed by a description of the findings and discussion of the results and key contributions of the study concerning previous research. Based on this study I will argue that the engagement imperative within music industry communication affects communication practitioners' work. The study specifically addresses the worker's experiences of the pressure to use music fans and their engagement as a marketing tool, based on the prerequisites of the contemporary online participatory culture.

\section{Theoretical Framework}

In line with calls for a deeper understanding of communication work in a participatory culture (see, for example, Brodmerkel \& Carah, 2016; Edwards, 2018), this section discusses theories on work, competences, skills, and identities, as well as facets of co-creation in strategic communication. This article relates to what can be seen as two suggested engagement turns-first, an engagement turn in work and, second, an engagement turn in strategic communication.

The framework of Anteby et al. (2016) uses three lenses-the "becoming," "doing," and "relating"-to discuss the parts and perspectives of professions. The becoming lens refers to processes of socialisation within an occupational community into shared cultural values, norms and world views. This lens also refers to becoming controlled and unequal-stressing organisational dynamics. The doing lens focuses on what kind of work and activities occupational members do "that have consequences for individual, occupational and organisational outcomes (such as shifts in jurisdiction, status, power and resource allocation)" (Anteby et al., 2016, p. 200). It has implications for the sense of identity, meaningful work and dignity of the worker. The relating lens refers to how the collaborative relationships that workers build with others (other occupational and non-occupational groups) also define them. This lens explains the generative nature of occupational and often collaborative and coproducing relationships. Using this framework can contribute to the understanding of communication work from multiple perspectives: individual, social, and contextual.

\subsection{The Engagement Turn in Work: Competences, Skills, Identities, and Ethics of Communication Professionals}

"Work" is going through transformation overall due to technological, political-economic, and organisational aspects within digital capitalism. Many workers-in this case, communication professionals-operate in a complex environment, with constantly changing contexts, relationships, demands, and pressures of consumers, clients, and colleagues (Deuze, 2009). There is also a liquefication of boundaries and practices in communication work. Professional fields like PR, marketing, branding, and social media management are often intertwined 
due to common grounds, challenges, and aims (Hallahan et al., 2007).

The concept of media work is used for cultural production taking place in a media logic (Deuze, 2007; Snow \& Altheide, 1979). It is "forms and processes that organise the work done within a particular medium...with cultural competence and frames of perception of audiences/users, which in turn reinforces how production within the medium takes place" (Dahlgren, 1996, p. 63). The media worker is executing a constant interaction and negotiation between creativity, connectivity, content, and commerce-they are a "culture creator" (Deuze, 2009). Within the music industry, this tension is prominent. Hesmondhalgh and Baker (2011) define the "cultural worker" within, for example, the music industry as creative labour centred on activities of symbol making and interpretive knowledge such as journalism, PR, and advertising. These creative workers (writers, editors, designers, producers, managers, musicians-and communicators) all produce "creative outputs" and mediated communication. As creative workers, according to Hesmondhalgh and Baker, tend to care greatly about their products, the individual striving and satisfaction to do "good work" (2011, p. 182) with quality that is socio-culturally significant, is also central to understanding their driving forces and sense of responsibility.

Regarding work as a whole, there is a shift in focus towards the individual worker's responsibility and accountability. There are also accelerated demands on the individual worker to balance the work environment and an expanding range of expected characteristics (Malmelin \& Villi, 2017; Sennett, 1998), which becomes part of the professional identity of the worker (Deuze, 2008; Miscenko \& Day, 2016). The professional identity forms out of the image of the ideal worker, emphasising values and desired characteristics such as being efficient, productive, autonomous, creative, flexible, responsible, self-optimising, and entrepreneurial (Baym, 2018; McRobbie, 2018). Fuller et al. (2018) suggest that excellent professional communication is signified by being strategic, empathetic, expressive, decisive, and able to see interrelationships. These traits become something to strive for and desirable feelings, values, and behaviours (both from a personal and collective view) that form one's identity (Alvesson et al., 2008) negotiated through a dynamic "internal-external dialectic" (Jenkins, 2014, p. 18) and affected by contextual factors, for example, technology. When researching journalists, Deuze (2008) finds that participatory and convergence culture impact both the structure (like standards and set routines, hierarchies, protection by law, ethical guidelines, etc.) and the worker's subjectivity (socio-demographic background, motivation, role models, identity, etc.). These changes also force professionals to develop new skills and competencies (Mykkänen \& Vos, 2017) that are increasingly diverse and complex (Cornelissen, 2008). Communicational skills and competences are at the centre: relationship building, project leading, planning, etc., as are technological competences, such as managing social media and data analytics. Jeffrey and Brunton (2010) argued that the most important skill of PR professionals is adaptability, indicating flexibility and a willingness to learn. Leadership and the ability to think strategically are also seen as central (Grunig, 1992; Grunig \& Grunig, 2006; Verhoeven et al., 2011). Altogether, characteristics, skills, and competences are part of what forms the professional practitioner's practice. It is both learnt in professional education and socialised within work contexts.

Expectations and public interpretations of the communication practitioner change and vary. On the one hand, they can be negatively associated with persuasion and manipulation (Hackley, 2007), doing "dirty work" (Ashforth et al., 2017), following orders and, therefore, subordinating any ethical judgments of their own (Botan \& Trowbridge, 2015). On the other hand, PR professionals can be seen as "ethical guardians" (L'Etang, 2011)advocating for public opinion and building prerequisites for dialogue. Regarding these opposing views and the challenges of the work at large, ethical aspects of the profession are increasingly discussed (see, for example, Drumwright \& Murphy, 2009). Social media has brought new ethical challenges, potential legitimacy gaps are more apparent, and unethical behaviour is more easily discovered and propagated online. L'Etang (2011) summarised actual key ethical issues, such as manipulation and inauthenticity, through the practices and assumptions of promotional culture. However, ethics online is only modestly discussed in communication research (see, for example, Sebastião et al., 2017; Toledano \& Avidar, 2016). Communication practitioners need to assess and adjust their social media practices and provide "ethical, responsible advice to their organisations," according to Valentini (2015, p. 175). These different results imply that ethical aspects of communication work in social media are complicated and require further investigation along with other social and contextual aspects of communication work.

\subsection{The Engagement Turn in Strategic Communication}

Strategic communication focuses on how an organisation presents and promotes itself to its audiences through intentional activities (Hallahan et al., 2007; Holtzhausen \& Zerfass, 2013). All organisational communication, according to Deetz (1992), has both goals and normative ideals of both participation and effectiveness. Building on the arguments of Deetz (1992), Torp (2015) claimed that it is important to keep this dual focus on communication. When the real goal of participation is effectiveness instead of participation (which is used as a tactic for reaching effectiveness), participation becomes instrumentalised. When strategic communication is seen and practised as a participatory process that can also emerge from below, individuals have the potential to be central actors in participation, instead of effectiveness. 
In this latter view, strategic communication is a recurrent process in which an organisation and its audiences negotiate meaning through dynamic and co-creational exchanges (see, for example, Botan, 2018). This view is also central in a participatory culture enabling and fostering engagement and in so-called "transmedia marketing" and "storytelling," where narratives expand and are co-created across media forms (Jenkins, 2006).

The view of and expectations of audiences have changed over the years, from being seen as passive and susceptible to influence to being seen as free and active agents choosing what media to consume and when, making their own meanings from content and creating their own (Jensen \& Rosengren, 1990; Livingstone, 2003). It has been profoundly discussed that audiences in their activities are being exploited as free labour by organisations (Terranova, 2000; Van Dijck, 2009) and are seen as commodities, where brands use their audiences' creative capital and the data audience engagement generates as valuable recourses for their own needs (Arvidsson, 2006; Nieborg \& Poell, 2018; Smythe, 1981/2006). Participatory cultures have also been discussed (see, for example, Carpentier, 2011) as both power producers and relatively powerless, and the producers, as having power over "official" media texts as well as the audience itself. What is called "fan culture" is what the media industry calls "user-generated content." Users make the content, and the industry makes the profit (Jenkins, 2009). Nonetheless, the focus on an active audience is still valid in contemporary audience discourses. There are imagined user modes: to use Bengtsson's (2012) terminology, users (audiences) should be active and engaged regarding digital media are. Thus, organisations that account for the engaging potential of social media "have clear advantage in building and upholding long-term relationships" (Falkheimer \& Heide, 2015, p. 342) and reach the ideal of so-called "symmetric communication" (Grunig \& Grunig, 2006). Engagement has become imperative to strategic communication.

As a consequence, communication practitioners are also increasingly seen as "social" communicators who initiate interaction and meaning creation between the organisation and the audiences (Falkheimer et al., 2017; Phillips \& Freeman, 2010). They can be seen as cultural intermediaries (Bourdieu, 1984) - "taste makers" working in the intersection of economy and culture, adding value and constructing legitimacy to today's marketplace, and in so doing leveraging their own personal experiences into occupational resources. The strategic communication professional balances the individual responsibility and competing demands of commerce and creativity with the actual communication work, where both strategy and audience relationships are central and constantly negotiated.

The music industry, more specifically, early on understood and adapted to digital platforms and social media prerequisites and their affordances (Choi \& Burnes,
2013; Van Dijck, 2009; Wikström, 2009). New, sophisticated methods and strategies to increase engagement using audiences and fandom as a marketing device have been increasingly developed (Gamble \& Gilmore, 2013; Gamble et al., 2019). Music fans generally have engaged relationships with popular culture and mediated artefacts (see Holt, 2004): Fans enjoy, participate with, and are often deeply involved in music artists, their music, and other fans (Baym, 2018; Carah, 2010; Duffett, 2013). Baym (2018, p. 1) claims that musicians are "under pressure to build connections with listeners" and to "be constantly accessible, especially on social media, offering unique and intimate moments to their fans." Therefore, strategies of both engagement and control are required for music brands, according to Baym (2018). In a music campaign, a range of media formats is used to provide a controlled and coherent (marketing) narrative with the aim to engage fans through co-creation (Edlom \& Karlsson, 2021; Jenkins, 2006). Communication and marketing are also highly adapted to and organised around data-driven processes where content is "continuously reworked and repackaged, informed by datafied user feedback" to be optimised for platform distribution and monetisation (Nieborg \& Poell, 2018, p. 4275). The work, itself, is therefore adapted both to the user-driven/engagement focus and the data that engagement produces, which is looped back into strategic considerations.

\section{Methods}

\subsection{Research Design and Data}

To attain a wider understanding of communication work and roles within the music industry, a qualitative focus is employed. A combined methodology was used: qualitative interviews and qualitative content analyses of music industry data.

The study was partly based on semi-structured interviews with music company representatives working with management, branding, and communication, as well as PR consultants in the field, on different professional levels. Interviews allow the researcher to get closer to their experiences and perceptions (Kvale \& Brinkmann, 2009) - to understand processes, social relationships, and deeper meanings. In total, 18 interviews were conducted between 2016 and 2021, with both men and women of various ages and stages of their professions in Sweden, the UK, and the US. Interviews lasted between 30 and 65 minutes and were audio-recorded and transcribed. Contracts were signed and the respondents' anonymity was ensured throughout the process of collecting, analysing and presenting data. The respondents were chosen from a combination of variation selection (they represent a width of the phenomenon) and type selection (they represent the typical within the specific phenomenon) to find patterns in the phenomenon of communication work in the music industry. This 
selection was partly made by convenience sampling and snowball sampling.

To understand the communication system of the music industry and the business view of the audience, I try to grasp discursive practices within the industry as emerging in the interviews and industry texts. Discourses are representations of the world, constituted of semiotic systems that provide a specific understanding of a reality to social actors and contribute to establishing and maintaining power structures (Foucault, 1969). As part of the analysis, I also use textual data from the environment of study and public documentation made by the music marketing firm Music Ally. This PR firm has specialised in communicating to music audiences and has become influential in the music industry by distributing "daily news and weekly insight briefings that are relied upon by thousands of music and tech execs around the world; covering markets, technologies, trends, and viewpoints that are shaping the modern industry" (Music Ally, 2020). Newsletters and reports from this firm (which can be seen as representative of the music industry and its current debates), targeted at other music companies and actors, were subjected to a qualitative analysis that considered written discourse. The material was collected between October 1, 2018, and July 30, 2019, and consisted of a daily digital newsletter (The Music Ally Bulletin) and a monthly report (Sandbox - the digital music marketing magazine), sent via email to subscribers worldwide. This textual industry data were contrasted and compared with the interview data and related to theoretical discussions regarding communication work and audience engagement.

\subsection{Data Analysis}

The data analysis was performed under the methodology of Gioia et al. (2013), an inductive and systematic approach to concept development that enables scientific theorising about people's experiences. Inspired by grounded theory (Strauss \& Corbin, 1990) and its constant comparative method, the approach provides a way to identify rich theoretical descriptions of the context within which the phenomena occur, guided by respondents' thoughts, intentions, and actions. The research process was characterised by an iteration between the data collection and analysis. All data were examined with a qualitative content analysis that identified similarities and differences among relevant topics and categories, which were then described and interpreted. As recommended by Gioia et al. (2013), I started the data analysis by coding the data set, identifying empirical codes and constructing empirical phrases closely related to the respondents' descriptions. I then constructed second-order themes by combining empirical explorations with theoretical reflections on communication work/practices, skills, roles, and identity, followed by aggregate dimensions and key themes. I worked through the interviews and the industry material in a sim- ilar way, and I ultimately compared and contrasted the two data sets, looking for overlaps, similarities, and differences, to understand the communication worker and today's conditions. These themes and aggregate dimensions are explored and described in the following results section and elaborated on in the discussion section concerning the chosen theoretical framework and concepts.

\section{Results}

This section discusses communication work within the music industry about audience engagement, with a focus on communication practitioners' experiences with their work.

\subsection{Becoming: Learning to Be a Communication Practitioner}

The data shows that the competences, skills, and characteristics demanded of the communication practitioners are constantly changing, which puts demands on them to keep up with what is expected and which values to adhere to (as suggested by Anteby et al., 2016). A communicator in the music industry is well educated and also supposed to be adaptive, social, creative, flexible, strategic, analytic, and relationship building, which reflects the traits of an excellent professional communication (Fuller et al., 2018) and a creative worker (Deuze, 2009). They are supposed to constantly build audience engagement-to be a social communicator (Phillips \& Freeman, 2010), strive for "symmetrical communication" (Grunig \& Grunig, 2006) and, meanwhile, strategically analyse the data that engagement brings.

The communication work is overall professionalised. Although, in smaller companies, it is more common for one person to have many tasks, whereas in bigger companies, the workforce is more specialised. In-house bureaus are also often built to create promotional content (photoshoots, ads, social media posts, album covers, etc.) at a fast pace and to "be more cost-efficient" and "creatively flexible." Quite a few of the respondents were young or had rather short experiences in the occupation (2-10 years). Hence, many are digital natives to whom digital media are natural. Although they have no firsthand experiences with the digital turn, they still reflect on this. Bella (head of social media marketing, 31) claims:

When I started working with this in 2015...there were no social media specialists [at the company]....Today you need a certain type of excellence to keep up. You need to be much more tech-savvy [than before]. Everything happens so fast, so you need people who can be focused all the time on this and that keep educating themselves.

The pace, the technological level and the demands on competences are seen as challenging: "A huge trial," as a young brand manager from a major music company puts 
it or "one big learning curve" (Music Ally, 2019a). Among the respondents, there was an expressed fatigue regarding constantly new technical solutions, although there was an acceptance that new platforms would arrive and that there was never enough time to catch up. Marketers "should be excited about the potential of new technologies" (Music Ally, 2018a). Respondents are optimistic about fast technological development, but is also concerned about the demands of being constantly up to date and online "24/7."

The accelerating demands of a relational, fast, competitive, technology-driven, and liquefied work environment to be an "ideal worker" put high pressure on individual communication practitioners. The findings indicate that although music industry communication practitioners are supposed to be experts in digital communication and consumer targeting, they express a lack of deeper understanding of the new work requirements. Many respondents pointed to the fact that the work changes place a larger demand on everyone involved: "You can never let your guard down" (Tomas, manager/communicator, 49). In the structure they are in, the development and demands also affect the professional's self-image, the professional identity, and the work identity of the communication worker (Miscenko \& Day, 2016). As the demands to create engagement and all the competences needed to do this are seen as a duty or an imperative, the demands need to be translated into meaningful actions, values and ideas that constitute the professional identity as a media worker.

\subsection{Doing: Working With Strategic Communication and Marketing in the Music Industry}

Popular music brands are built and communicated as a joint effort; by the artist, agent, the music company (its management, communicators, marketers, and creatives), and often PR, advertising, and media consultants. The actual work comprises value formulation and long-term strategic artist branding and narrative formulation, as well as day-to-day practices of communication and advertising, both in digital (web, social media, streaming services, etc.) and traditional media (print, TV, radio advertising, sponsorship agreements, etc.). A communication worker's day can include creating content and buying ads for Facebook, Instagram, and TikTok, analysing generated social media data, and following and interacting with fan communities. The data show that communication work is clearly focused on building relationships and creating audience engagement (Botan, 2018; Gamble \& Gilmore, 2013). Most of the respondents emphasised the need for dynamic strategies in the social media environment: to be able to react to audience actions, to listen to and "follow" the audience, and to adjust the communication strategy if needed, in a fluid way.

The data suggest that, with increasing demands on social media and platform content creation to engage the audience, actual professional roles are expanding and most often include both traditional communication and marketing. Those who used to be PR or marketing professionals can now work as, for example, a creative and marketing director, president of strategy, Internet community manager, senior content creator, or head of social media marketing. Both broad competences and excellence are required. Being a strategist, communicator, content creator, and coach/educator for the artists in their platform usage, all simultaneously, is the norm. Bella (head of digital marketing, 31) was working both with the "organic" parts of social media (the communication and content creation) and the advertising part, such as media buys and the connected analytics. John (VP of strategy, 49) was responsible for consumer insight, data analytics, and brand partnerships. There were considerably larger responsibilities than before, which also goes in line with Anteby et al. (2016).

The communication professional is seen as a (silent) key player between the music company, the audience, and the platforms. Nevertheless, the constant striving to "build engagement" is seen as challenging: to create interesting content and appear interesting to audiences. Adam (CEO at management, 55) claims that "this is the goal of our social media platform...is to fit into their narrative." To do this, there is a need to know "what the fans are thinking, doing, and talking about," according to Ali (head of insight, 44). This requires spending time with them on the platforms. Anna (head of creative, 32) noted:

We need to live in the same world as the target group. We need to inject our presence there. It is an unwritten part of our work description to increase the number of followers and to keep the fans active.

There are not only expressed challenges but also positive aspects of the work: Several of the respondents expressed pride in being able to create successful communication and be part of creative teams, in doing "good work" (Hesmondhalgh \& Baker, 2011), close to fans. Sandra (head of brand partnership, 29) explains: "Check out that content! It was outstanding." It is also often seen as exciting to work with communication in the music industry, with a close connection to both music and the music fans. The view is that these kinds of jobs are desirable and that there are many applicants in line, "hungry" for the jobs.

\subsection{Relating to Audiences: Expected Audience Modes}

The data suggest that it is important to involve audiences in the communication and brand building of music artists. To have a dialogue with audiences and to follow them in their "natural arena": "These people are so excited. We just follow them and amplify what they were doing" (Erica, communicator at management, 28). It is "fans first" and the most engaged are always in focus. Music 
audiences are generally seen as being really interested and invested in music, and "it is much easier to build relationships with someone that is interested" (Johan, CEO PR firm, 38). The "expected user modes" (Bengtsson, 2012) is audiences having agency and impact, and wanting to contribute and take part. The audience is generally seen as getting better and better in creating content and in being selective in their approach. You have to "give the fans credit," expressed Phil, a PR specialist (42). Many respondents point to the fact that they are aware of being part of the communication around an artistthey know when they are being exploited and not getting something in return, and then will leave. Ali (head of insight, 44) claims: "Fans have a very eager nose for fakery...for bullshit."

At the same time, audiences are seen as tools and key resources for strategic communication. To involve them in the communication around a music brand is seen as necessary-a fact, not a choice. The communication work centres on "approaching" and "pleasing" the audience to increase and "cultivate fan engagement," "tie in with fanbase," to get a "following," to "amplify," "trigger," "target," and to steer and "drive subscribers" and "traffic" (Music Ally, 2018b, 2019a, 2019c). The aim is "making social marketing smarter and more streamlined" to serve music brands (Music Ally, 2018c). This must be done in a considerate way, according to many of the respondents: "You need to be extra smart, to pursue them in a way that makes it possible to not pay them and make them do it out of their own interests," Anna (head of creative, 32) claims. Nevertheless, this view implies an uneven, asymmetrical, power relationship between the organisation and the audience, not a symmetric one. Focus is the industrial benefit of audience engagement, not the engagement, itself.

The question about whether the audience is actually working for the brand (as suggested by, for example, Van Dijck, 2009) is debated within the music industry as well as by the respondents in this study. Sometimes audiences are actually paid (for example, work in "street teams"), but most of the work is done for free, out of "interest," because they "want to help":

We have a girl in Russia who, whenever we do campaigns there, will translate and post for us. And she does it for free because she is interested. But of course, we give her rewards and treats like firsthand information and content, because...it's win-win. (Bella, head of social media marketing, 31)

Some respondents were ambiguous, or not concerned at all, regarding the fact that audience engagement translates into free marketing: "My focus is to help the artist to achieve their vision with the brand....Much more than that, I don't think about it" (Christopher, senior content creator, 27). Others are clearly concerned: "They [the audiences] are doing work that means that we can spend less....We're actually using them" (John, VP of strategy, 49). "Of course, the fans are working for the brand....Or, rather, they're ambassadors," suggests Stefan (management, 48). The general view among the respondents is that audiences need to be told when using their engagement and input into marketing campaigns and tell them about the prerequisites, although this is often overlooked. Altogether, this suggests that, in theory, the self-image of being a communication practitioner tends towards wanting to be a responsible cultural intermediary (as according to Bourdieu, 1984) and aware of the pitfalls of the work regarding using audiences. In practice, this is sometimes harder to achieve: The tempo, complexities, and insecurities of everyday work performances entangled in digital platform structures, big data flows, and networked relationships make it hard to focus on social and ethical factors. The human side of the audience gets out of focus.

Ethical aspects and concerns were discussed by some of the respondents-what is ok to do, regarding the audience. Some respondents expressed concerns about, using and/or exploiting the audiences' engagement: pushing and steering them into activity within a campaign, collecting the data they generate, and using the co-created fan content without their awareness. During the process, they also collect fans' personal data and personalise digital advertising, often without them knowing it. Many of the respondents expressed confusion regarding ethics along with an acceptance of the conditions. Anna (head of creative, 32) stated: "It is a matter of getting into the conversation and camouflaging ourselves in it. It sounds terrible, as if we are an enemy, but it is how marketing works." Nevertheless, some asked for more discussions about ethics in their organisations and in the industry. Clear ethical guidelines are sought for (although often non-existent): "Fan engagement opens up a strange ethical space: What is ok or not ok to ask people to do. It's a new territory, but there aren't a set of ethical or moral guidelines, which is quite scary," John (VP of strategy, 49) elaborates.

One example where ethics have come further is the privacy aspect: Here, new laws on General Data Protection Regulation have forced the industry to adapt and learn (see, for example, Music Ally, 2019b). One platform representative explained: "We are helping marketers take more control over how they can retarget audiences." Coming up with and understanding new regulations and new practices that work within them is possible, although complicated. Yet, some respondents were so concerned with the business practices and had even changed companies when finding the fan exploitation too harsh. Bella (head of social media marketing, 31) says: "We are working with living material, with humans....Therefore, I eventually changed to a smaller music company, to get to work closer to music and people, and being less commercially steered." Others think that the music industry is better than other industries. The commercial popular music industry seems to partly represent cultural values and a humanistic approach to 
all the respondents, although the ethical limits for how to approach the audiences vary. Even this part of the work, using the relating lens by Anteby et al. (2016), shows that the collaborative relationships built with audiences define the professionals. In summary, the professionals seem to have difficulties navigating the opposing views of and interaction with the audience: The commercial and cultural sides are colliding, which is in line with Deuze's (2009) view on being a media worker and culture creator, to be in constant negotiation between creativity, connectivity, content, commerce, and the use of audience engagement.

\section{Conclusion and Discussion}

This article discusses communication practitioners' experiences working within contemporary participatory culture-the popular music industry-with its mediatised modes of communication production, dependent on audience engagement. By addressing calls for understanding the sociocultural aspects of strategic communication work, the article answers questions about how experienced roles and responsibilities affect the work, the worker, and the profession itself. How to become and be a communication practitioner (i.e., the becoming and doing of the framework by Anteby et al., 2016) is affected by socialisation in the occupational community-to learn what is expected and which norms and values to adhere to. It is also affected by what is required to work with communication-new skills, competences, practices, work methods, and tools being used. When trying to measure up with both internal and external demands on being cooperative, flexible, creative, strategic, effective and decisive (as suggested by, for example, Fuller et al., 2018; McRobbie, 2018), professional identity is affected.

The study shows that all parts of communication work are affected by participatory culture, the anticipation of active audiences, and ultimately by an engagement imperative. The normative ideals of commercial and strategically steered artist brands, via audience engagement, have become imperative. All sorts of organisational communication are built on the precepts of creating engagement among their audiences, to involve them in dialogue and co-creation around the brand in the brand's interest. Building engaging brands is a duty, and relying on audience engagement in the communication work is seen as the only way to do it, according to the respondents in this study. Nonetheless, there are tensions: Even if capitalist organisations demand collaboration and creativity from the worker, there seems to be less place or time for being empathetic (i.e., focus on the human behind the number), subjective, or critical (Gill \& Pratt, 2008).

In this study, there is an expressed struggle between different requirements and discourses, which also reflects the current discourse of the music industry regarding their audiences. On the one hand, there is an active audience and endless interactions on social media. On the other hand, the audience is steered by commercial interests and platforms. For organisations, reaching an audience is hard work that must be done. According to Music Ally (2018c), it is the "smart ones" who are "working around the rules" that succeed in leading the audience. Here, the "blessing" is understanding the systems, to be able to bypass them and strategically reach the audiences better, and understanding their actions via data gathers, not really getting to know them better or respect them more. This reflects an asymmetrical view of the audiences, not at all the ideal symmetric one, suggesting that the power structures are still rather intact within communication. Communication practitioners and their organisations still manoeuvre the co-creative relationship with the audience. The goal of engagement is effectiveness rather than participation, according to the results of this study. As such, the imagined audience modes and expectations of the audience engagement inform how the requirements to produce engagement affect the communication work and worker and the norms and considerations they face. One example is ethics, that even though it is discussed by the respondents and within the industry data, is not in focus. Creating engagement has clear ethical implications for both media workers and the audience, and some of the respondents express that they want to reflect ethical and empathetic behaviours (Alvesson et al., 2008). They want to convey themselves as ethical guardians (L'Etang, 2011) or advocates. Although, when Valentini (2015) suggests that communication workers advocate for ethics within the organisation, this is seldom the case according to this study, and there is a lack of ethical competences.

If communication professionals constantly are pushed to develop, change, go-between views and morals, and even bend rules, are they getting prone to problematise the conditions they work within? A further ethical discussion about audience engagement and clearer ethical guidelines regarding what communication practitioners can and cannot do is important to keep evolving in both the academic and the professional strategic communication field. Further research should continually supply alternative discourses regarding the relationships between the industry and their audiences - to broaden and problematise the views on both the workers and the audiences as human beings in a complex society. There is a possibility for a more sustainable music industry truly interested in those they are relating to. For this, there is a need for contextualisation and an understanding of social, economic, and cultural aspects, as well as getting closer to the study objects. The engagement imperative should also be discussed in other industries. Music fans as audiences are generally highly engaged with music, musicians, and ultimately music brands-presumably more engaged and entangled with the brands than customers with many other kinds of brands in other industries (although there are some exceptions of deep and fanlike consumer engagement, for example in sports (Guschwan, 2012) and luxury 
goods (see, for example, Cova et al., 2015). Nevertheless, although relationships with audiences might look different and be on different engagement levels, organisations in different industries are facing the same challenges and there might be similar implications regarding engagement in a contemporary digital arena.

\section{Acknowledgments}

The study has been conducted as a part of the research project Music Ecosystems Inner Scandinavia, funded by the Interreg Sweden-Norway programme, EU, and Karlstad University, Inland Norway University of Applied Sciences, Innlandet Fylkeskommune County Council, Arvika municipality, and Region Värmland.

\section{Conflict of Interests}

The author declares no conflict of interests.

\section{References}

Alvesson, M., Lee Ashcraft, K., \& Thomas, R. (2008). Identity matters: Reflections on the construction of identity scholarship in organization studies. Organization, 15(1), 5-28.

Andrejevic, M. (2014). The big data divide. International Journal of Communication, 8, 1673-1689.

Anteby, M., Chan, C. K., \& DiBenigno, J. (2016). Three lenses on occupations and professions in organizations: Becoming, doing, and relating. Academy of Management Annals, 10(1), 183-244.

Argenti, P. A., Howell, R. A., \& Beck, K. A. (2005). The strategic communication imperative. MIT Sloan Management Review.

Arvidsson, A. (2006). Brand, meaning, and value in media culture. Routledge.

Ashforth, B. E., Kreiner, G. E., Clark, M. A., \& Fugate, M. (2017). Congruence work in stigmatized occupations: A managerial lens on employee fit with dirty work. Journal of Organizational Behavior, 38(8), 1260-1279.

Asunta, L. (2016). The role, the goal, and the soul of professional public relations: Developing a holistic model of PR professionalism. University of Jyväskylä.

Barger, V., Peltier, J. W., \& Schultz, D. E. (2016). Social media and consumer engagement: $A$ review and research agenda. Journal of Research in Interactive Marketing, 10(4), 268-287.

Baym, N. K. (2018). Playing to the crowd: Musicians, audiences, and the intimate work of connection. New York University Press.

Bengtsson, S. (2012). Imagined user modes: Media morality in everyday life. International Journal of Cultural Studies, 15(2), 181-196.

Botan, C. H. (2018). Strategic communication theory and practice: The cocreational model. Wiley.

Botan, C. H., \& Trowbridge, J. G. (2015). Public rela- tions theory: Past, present, and future. In R. Fröhlich, P. Szyszka, \& G. Bentele (Eds.), Handbuch der Public Relations [The public relations handbook] (pp. 357-377). Springer VS.

Bourdieu, P. (1984). Distinction: A social critique of the judgment of taste. Harvard University Press.

Brodmerkel, S., \& Carah, N. (2016). Brand machines, sensory media, and calculative culture. Springer.

Broersma, M. (2019). "Audience Engagement." In T. P. Vos, F. Hanusch, \& D. Dimitrakopoulou (Eds.), The international encyclopedia of journalism studies. Wiley.

Carah, N. (2010). Pop brands: Branding, popular music, and young people (Vol. 11). Peter Lang.

Carpentier, N. (2011). Media and participation: A site of ideological-democratic struggle. Intellect.

Choi, H., \& Burnes, B. (2013). The internet and value co-creation: The case of the popular music industry, Prometheus, 31(1), 35-53.

Cornelissen, J. (2008). Corporate communication: A guide to theory and practice. SAGE.

Cova, B., Pace, S., \& Skålén, P. (2015). Marketing with working consumers: The case of a carmaker and its brand community. Organization, 22(5), 682-701.

Dahlgren, P. (1996). Media logic in cyberspace: Repositioning journalism and its publics. Javnost the Public, 3(3), 59-72.

Deetz, S. (1992). Democracy in an age of corporate colonization: Developments in communication and the politics of everyday life. SUNY Press.

Deuze, M. (2007). Media work. Polity Press.

Deuze, M. (2008). Professional identity in a participatory media culture. In T. Quandt \& W. Schweiger (Eds.), Journalismus online: Partizipation oder Profession? [Journalism online: Participation or profession?] (pp. 251-261). Springer.

Deuze, M. (2009). The media logic of media work. Journal of Media Sociology, 1(2), 22-40.

Drumwright, M. E., \& Murphy, P. E. (2009). The current state of advertising ethics: Industry and academic perspectives. Journal of Advertising, 38(1), 83-108.

Duffett, M. (2013). Introduction: Directions in music fan research. Undiscovered Territories and Hard Problems. Popular Music and Society, 36(3), 299-304.

Edlom, J., \& Karlsson, J. (2021). Hang with me: Exploring fandom, brandom, and the experiences and motivations for value co-creation in a music fan community. International Journal of Music Business Research, 10(1), 17-31.

Edwards, L. (2018). Understanding public relations: Theory, culture, and society. SAGE.

Elmer, P. (2011). Public relations and storytelling. In L. Edwards \& C. E. M. Hodges (Eds.), Public Relations, Society \& Culture (pp. 59-72). Routledge.

Falkheimer, J., \& Heide, M. (2015). Strategic communication in participatory culture. In D. Holtzhausen \& A. Zerfass (Eds.), The Routledge handbook of strategic communication (pp. 337-349). Routledge. 
Falkheimer, J., Heide, M., Nothhaft, H., Von Platen, S., Simonsson, C., \& Andersson, R. (2017). Is strategic communication too important to be left to communication professionals? Managers" and coworkers" attitudes towards strategic communication and communication professionals. Public Relations Review, 43(1), 91-101.

Foucault, M. (1969). L'archéologie du savoir [The archaeology of knowledge]. Gallimard.

Fuller, M., Heijne-Penninga, M., Kamans, E., van Vuuren, M., de Jong, M., \& Wolfensberger, M. (2018). Identifying competence characteristics for excellent communication professionals: A work field perspective. Journal of Communication Management, 22(2), 233-252.

Gamble, J., \& Gilmore, A. (2013). A new era of consumer marketing? An application of co-creational marketing in the music industry. European Journal of Marketing, 47(11/12), 1859-1888.

Gamble, J. R., McAdam, R., \& Brennan, M. (2019). How user-centric innovation is affecting stakeholder marketing strategies: Exploratory findings from the music industry. European Management Review, 16(4), 1175-1193.

Gill, R., \& Pratt, A. (2008). Precarity and cultural work in the social factory? Immaterial labour, precariousness, and cultural work. Theory, Culture \& Society, 25(7/8), 1-30.

Gioia, D. A., Corley, K. G., \& Hamilton, A. L. (2013). Seeking qualitative rigor in inductive research: Notes on the Gioia methodology. Organizational Research Methods, 16(1), 15-31.

Grunig, J. E. (1992). Excellence in public relations and communication management. Lawrence Erlbaum Associates.

Grunig, J., \& Grunig, L. (2006). The future of excellence in public relations and communication management. Lawrence Erlbaum Associates Inc.

Guschwan, M. (2012). Fandom, brandom and the limits of participatory culture. Journal of Consumer Culture, 12(1), 19-40.

Hackley, C. (2007). Marketing psychology and the hidden persuaders. Psychologist-Leicester, 20(8), 488-491.

Hallahan, K., Holtzhausen, D., van Ruler, B., Verčič, D., \& Sriramesh, K. (2007). Defining strategic communication. International Journal of Strategic Communication, 1(1), 3-35.

Hesmondhalgh, D., \& Baker, S. (2011). Creative labour: Media work in three cultural industries. Routledge.

Holt, D. B. (2004). How brands become icons: The principles of cultural branding. Harvard Business Press.

Holtzhausen, D. R., \& Zerfass, A. (2013). Strategic communication: Pillars and perspectives of an alternative paradigm. In K. Sriramesh, A. Zerfass, J.-N. Kim (Eds.), Public relations and communication management (pp. 323-342). Routledge.

Ihlen, $\varnothing ., \&$ Verhoeven, P. (2015). Social theories for strategic communication. In D. Holtzhausen \& A. Zer- fass (Eds.), The Routledge handbook of strategic communication (pp. 127-140). Routledge.

Jeffrey, L., \& Brunton, M. (2010). Identifying competencies for communication practice: A needs assessment for curriculum development and selection in New Zealand. Public Relations Review, 36(2), 202-205.

Jenkins, H. (2006). Fans, bloggers, and gamers: Exploring participatory culture. New York University Press.

Jenkins, H. (2009). Confronting the challenges of participatory culture: Media education for the 21st century. MIT Press.

Jenkins, R. (2014). Social identity. Routledge.

Jensen, K. B., \& Rosengren, K. E. (1990). Five traditions in search of the audience. European Journal of Communication, 5(2), 207-238.

Kiesenbauer, J., \& Zerfass, A. (2015). Today's and tomorrow's challenges in public relations: Comparing the views of chief communication officers and next generation leaders. Public Relations Review, 41(4), 422-434.

Kvale, S., \& Brinkmann, S. (2009). Interviews: Learning the craft of qualitative research interviewing. SAGE.

L'Etang, J. (2011). Public relations and marketing. Ethical issues and professional practice in society. In G. Cheney, S. May, \& D. Munshi (Eds.), The handbook of communication ethics (pp. 221-240). Routledge.

Livingstone, S. (2003). The changing nature of audiences: From the mass audience to the interactive media user. In A. Valdivia (Ed.), A companion to media studies (pp. 337-359). Basil Blackwell.

Malmelin, N., \& Villi, M. (2017). Media work in change: Understanding the role of media professionals in times of digital transformation and convergence. Sociology Compass, 11(7), Article e12494.

McRobbie, A. (2018). Be creative: Making a living in the new culture industries. Wiley.

Miscenko, D., \& Day, D. V. (2016). Identity and identification at work. Organizational Psychology Review, 6(3), 215-247.

Music Ally. (2018a). Sandbox issue 215: 'Boxing clever. Sandbox summit special issue. https://musically. com/2018/11/05/sandbox-issue-215-boxing-cleversandbox-summit-special-issue

Music Ally. (2018b). Sandbox issue 216: Tuning in. Connected TV marketing in focus. https://musically. com/2018/11/14/sandbox-issue-216-tuning-inconnected-tv-marketing-in-focus

Music Ally. (2018c). Sandbox issue 217: Transfer time. How to move fans from underperforming social channels. https://musically.com/2018/12/03/sandboxissue-217-transfer-time-how-to-move-fans-fromunderperforming-social-channels

Music Ally. (2019a). Sandbox issue 219: The tools and trends that will shape 2019. https://musically.com/ 2019/01/10/sandbox-issue-219-the-tools-andtrends-that-will-shape-2019

Music Ally. (2019b). Sandbox issue 225: Retargeting in an age of privacy. https://musically.com/2019/ 
04/03/sandbox-issue-225-retargeting-in-an-age-ofprivacy

Music Ally. (2019c). Music Ally bulletin, July 3, 2019 [Email Newsletter]. Music Ally.

Music Ally. (2020). News, insight and data. https:// musically.com/insight

Mykkänen, M., \& Vos, M. (2017). Clarifying skills and competencies in organisational decision making: Perceptions of Finnish communication professionals. In B. van Ruler, I. Smit, $\varnothing$. Ihlen, \&. S. Romenti (Eds.), How strategic communication shapes value and innovation in society. Emerald Publishing.

Negus, K. (2018). From creator to data: The post-record music industry and the digital conglomerates. Media, Culture \& Society, 41(3), 367-384.

Nieborg, D. B., \& Poell, T. (2018). The platformization of cultural production: Theorizing the contingent cultural commodity. New Media \& Society, 20(11), 4275-4292.

Phillips, R. A., \& Freeman, R. E. (2010). Stakeholders. Edward Elgar Publishing.

Scolari, C. A. (2009). Transmedia storytelling: Implicit consumers, narrative worlds, and branding in contemporary media production. International Journal of Communication, 3(3), 586-606.

Sebastião, S. P., Zulato, G., \& Santos, T. B. (2017). Public relations practitioners" attitudes towards the ethical use of social media in Portuguese-speaking countries. Public Relations Review, 43(3), 537-546.

Sennett, R. (1998). The corrosion of character: The personal consequences of work in the new capitalism. W.W. Norton \& Company.

Smythe, D. W. (2006). On the audience commodity and its work. In M. G. Durham \& D. M. Kellner (Eds.),
Media and cultural studies: Keyworks (pp. 230-256). Blackwell. (Original work published 1981)

Snow, R., \& Altheide, D. (1979). Media Logic. Beverly Hills, 8, 1094-1096.

Steensen, S., Ferrer-Conill, R., \& Peters, C. (2020). (Against a) theory of audience engagement with news. Journalism Studies, 21(12), 1662-1680.

Strauss, A. L., \& Corbin, J. M. (1990). Basics of qualitative research: Grounded theory procedures and techniques. SAGE.

Terranova, T. (2000). Free labor. Social Text, 18(2), 33-58.

Toledano, M., \& Avidar, R. (2016). Public relations, ethics, and social media: A cross-national study of PR practitioners. Public Relations Review, 42(1), 161-169.

Torp, S. M. (2015). The strategic turn in communication science: On the history and role of strategy in communication science from ancient Greece until the present day. In D. Holtzhausen \& A. Zerfass (Ed.), Routledge handbook of strategic communication (pp. 35-53). Routledge.

Valentini, C. (2015). Is using social media "good" for the public relations profession? A critical reflection. Public Relations Review, 41(2), 170-177.

Van Dijck, J. (2009). Users like you? Theorizing agency in user-generated content. Media, Culture \& Society, 31(1), 41-58.

Verhoeven, P., Zerfass, A., \& Tench, R. (2011). Strategic orientation of communication professionals in Europe. International Journal of Strategic Communication, 5(2), 95-117.

Wikström, P. (2009). The music industry. Polity Press.

Zeiser, A. (2015). Transmedia marketing. From film and $T V$ to games and digital media. Focal Press.

\section{About the Author}

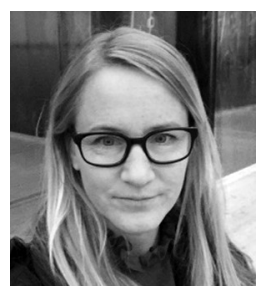

Jessica Edlom is a doctoral student in media and communication and an adjunct teacher at Karlstad University, Sweden. She is part of the EU-funded Interreg Sweden-Norway research project MECO: Music Ecosystems Inner Scandinavia. Her research is focused on strategic communication, communication management, and brand building. Prior to her career in academia, Jessica worked in advertising and strategic communication for both private and public organisations. 